\title{
The repair bond strength to resin matrix in cured resin composites after water aging
}

\author{
Dhaifallah ALQARNI ${ }^{1}$, Masatoshi NAKAJIMA ${ }^{1}$, Keiichi HOSAKA ${ }^{1}$, Kurumi IDE ${ }^{1}$, Daiki NAGANO ${ }^{1}$, Takehiro WADA², \\ Masaomi IKEDA ${ }^{3}$, Teerapong MAMANEE ${ }^{4}$, Ornnicha THANATVARAKORN ${ }^{5}$, Taweesak PRASANSUTTIPORN ${ }^{4,6}$, \\ Richard FOXTON ${ }^{7}$ and Junji TAGAMI ${ }^{1}$
}

\author{
${ }^{1}$ Department of Cariology and Operative Dentistry, Department of Oral Health Sciences, Graduate School of Medical and Dental Sciences, Tokyo \\ Medical and Dental University, 1-5-45 Yushima, Bunkyo-ku, Tokyo 113-8549, Japan \\ ${ }^{2}$ Department of Advanced Biomaterials, Oral Health Sciences, Graduate School of Medical and Dental Sciences, Tokyo Medical and Dental University, \\ 1-5-45 Yushima, Bunkyo-ku, Tokyo 113-8549, Japan \\ ${ }^{3}$ Department of Oral Prosthetic Engineering, Graduate School, Tokyo Medical and Dental University, 1-5-45 Yushima, Bunkyo-ku, Tokyo 113-8549, \\ Japan \\ ${ }^{4}$ Department of Restorative Dentistry and Periodontology, Faculty of Dentistry, Chiangmai University, T.Suthep, A.Meuang, Chiang Mai 50200, Thailand \\ ${ }^{5}$ Faculty of Dentistry, Bangkokthonburi University, 16/10 Leabklongtaweewatana Rd. Khet Taweewatana, Bangkok 10170, Thailand \\ ${ }^{6}$ Center of Excellence in Materials Science and Technology, Chiang Mai University, T.Suthep, A.Meuang, Chiang Mai 50200, Thailand \\ ${ }^{7}$ Restorative Dentistry, King's College London Dental Institute, King's College London, Floor 25, London Bridge SE1-9RT, London, UK \\ Corresponding author, Keiichi HOSAKA; E-mail: hosaka.ope@tmd.ac.jp
}

\begin{abstract}
The repair microshear bond strengths $(\mu \mathrm{SBSs})$ to resin matrices in 4 different cured-composites after water storage $(0,60 \mathrm{~s}, 1 \mathrm{week}$ 1 month) were evaluated. Three different adhesive application methods to the cured-composites were performed; (1) none, (2) onestep self-etch adhesive application, and (3) one-step self-etch adhesive application with a silane coupling agent. Degree of conversion (DC) of the composite discs was determined using ATR/FT-IR with a time-based spectrum analysis. Initially, the amount of unreacted resin monomers in the repaired cured-composite contributed to the bonding performance of newly-filled uncured-composite to resin matrix of the cured-composite. Adhesive application could not improve their repair $\mu$ SBS. After 1-month of water-storage, the repair $\mu \mathrm{SBS}$ was dependent on material, which either reduced or did not and was not influenced by their amount of un-reacted resin monomers. When repairing aged composite resin, the appropriate adhesive application procedures were different among resin composites.
\end{abstract}

Keywords: Repair bond strength, Water aging, Resin matrix, Adhesive application, Degree of conversion

\section{INTRODUCTION}

Direct resin composite restorations are increasingly placed in dental practice because of their good esthetics and superior bonding performance to tooth substrates. In accordance with the concept of minimal intervention and maximum preservation of tooth structure, repair of resin composite restorations is recommended instead of the complete-removal and replacement in cases of secondary caries, marginal defects and discoloration or discoloration of the resin composite itself $f^{1,2)}$.

The repair bonding performance between newly placed and aged polymerized resin composite restorations depends on three mechanisms: 1) chemical interaction with remaining un-reacted monomers in previously cured-composite; 2) micro-mechanical bonding by monomer infiltration into the cured-composite and 3) chemical bonding to exposed fillers on the curedcomposite surface ${ }^{3,4}$. Initially, the quantity of remaining un-reacted resin monomers in cured-composites would be influenced by the polymerization rate $^{5}$. Therefore, resin composite materials with lower rates of polymerization would offer an advantage for obtaining

Color figures can be viewed in the online issue, which is available at J-STAGE

Received Feb 8, 2018: Accepted Jun 4, 2018

doi:10.4012/dmj.2018-044 JOI JST.JSTAGE/dmj/2018-044 higher immediate repair bonding performance whereas a higher polymerization rate would be disadvantageous. However, these un-reacted monomers leach from the cured-composite during aging in the oral environment and therefore their ability to positively influence repair bonding performance would be gradually lost ${ }^{6}$.

Moreover, the resin matrix in cured-resin composite absorbs water during aging. The presence of water absorbed in cured-composite could interfere with the infiltration of hydrophobic monomers from the newlyplaced uncured composite into the cured-composite surface, leading to a reduction in the repair bonding performance. The application of a hydrophilic adhesive, such as a one-step self-etch adhesive may improve the repair bonding performance to water-aged curedcomposites. There have been many studies about the pre-treatment effect of a silane coupling agent on repair bonding performance to water-aged cured-composite, focusing on exposed fillers on resin composite surfaces ${ }^{7-9)}$. However, there have been fewer investigations on repair bonding performance to the resin matrix of water-aged cured-composites.

The objective of this study was therefore to evaluate repair bond strengths to the resin matrices of resin composites after water storage for $60 \mathrm{~s}, 1$ week and 1 
month. The null hypotheses tested in this study were that 1) there is no difference in repair bond strength between resin composites, and that 2) water-storage does not affect the repair bond strength of resin composites with and without application of a one-step self-etch adhesive.

\section{MATERIALS AND METHODS}

Microshear bond strength ( $\mu S B S)$ test

The materials used in this study are listed in Table
1. Four resin composites, Filtek Supreme Ultra (FSU; Shade A2, 3M, St. Paul, MN, USA), Estelite Sigma Quick (ESQ; Shade A2, Tokuyama Dental, Tokyo, Japan), Beautifil II (BE2; Shade A2, Shofu, Kyoto, Japan), and Clearfil AP-X (APX; Shade A2, Kuraray Noritake Dental, Tokyo, Japan) were used in this study. Figure 1 shows schematically how the specimens were prepared. A total of 24 discs of each brand of resin composite were prepared in this study. A transparent plastic matrix strip (Hawe Striproll Transparent $10 \mathrm{~mm}$, KerrHawe, Bioggio, Switzerland) was placed on the glass slide and

Table 1 Compositions of the materials used in this study

\begin{tabular}{|c|c|c|c|}
\hline Materials & Manufacturer & Compositions & Filler load \\
\hline $\begin{array}{l}\text { Filtek }^{\mathrm{TM}} \text { Supreme Ultra } \\
\text { Universal restorative } \\
\text { (FSU) }\end{array}$ & $\begin{array}{l}\text { 3M, St. Paul, } \\
\text { MN, USA }\end{array}$ & $\begin{array}{l}\text { Non-agglomerated/non-aggregated zirconia, silica, } \\
\text { Aggregated zirconia/silica clusters, Bis-GMA, } \\
\text { UDMA, TEGDMA, Bis-EMA, PEGDMA }\end{array}$ & $\begin{array}{l}78.5 \mathrm{wt} \% / \\
63.0 \mathrm{vol} \%\end{array}$ \\
\hline $\begin{array}{l}\text { Estelite Sigma Quick } \\
\text { (ESQ) }\end{array}$ & $\begin{array}{l}\text { Tokuyama Dental, } \\
\text { Tokyo, Japan }\end{array}$ & $\begin{array}{l}\text { Silica-zirconia fillers, Silica-titania fillers, } \\
\text { Bis-GMA, TEGDMA }\end{array}$ & $\begin{array}{l}82.0 \mathrm{wt} \% / \\
71.0 \mathrm{vol} \%\end{array}$ \\
\hline $\begin{array}{l}\text { Beautifil II } \\
\text { (BE2) }\end{array}$ & $\begin{array}{l}\text { Shofu, } \\
\text { Kyoto, Japan }\end{array}$ & $\begin{array}{l}\text { Aluminofluoro-borosilicate glass, S-PRG filler, } \\
\text { Bis-GMA, TEGDMA }\end{array}$ & $\begin{array}{l}83.3 \mathrm{wt} \% / \\
68.6 \mathrm{vol} \%)\end{array}$ \\
\hline $\begin{array}{l}\text { Clearfil AP-X } \\
(\mathrm{APX})\end{array}$ & $\begin{array}{l}\text { Kuraray Noritake } \\
\text { Dental, Tokyo, Japan }\end{array}$ & $\begin{array}{l}\text { Barium glass filler, colloidal silica filler, } \\
\text { Bis-GMA, TEGDMA }\end{array}$ & $\begin{array}{l}85.0 \mathrm{wt} \% / \\
71.0 \mathrm{vol} \%\end{array}$ \\
\hline Clearfil SE One & $\begin{array}{l}\text { Kuraray Noritake } \\
\text { Dental }\end{array}$ & $\begin{array}{l}\text { MDP, Bis-GMA, HEMA, hydrophobic DMA, } \\
\text { sodium fluoride, silanated colloidal silica, } \\
\text { accelerators, initiators, CQ, ethanol, water ( } \mathrm{pH} 2.3 \text { ) }\end{array}$ & - \\
\hline $\begin{array}{l}\text { Clearfil Porcelain Bond } \\
\text { Activator }\end{array}$ & $\begin{array}{l}\text { Kuraray Noritake } \\
\text { Dental }\end{array}$ & $\gamma$-MPTS, hydrophobic aromatic dimethacrylate & - \\
\hline
\end{tabular}

10-MDP: 10-Methacryloyloxydecyl dihydrogen phosphate, HEMA: 2-hydroxyethyl methacrylate, Bis-GMA: bisphenol-Aglycidyl methacrylate, TEGDMA: triethyleneglycol dimethacrylate, PEGDMA: Poly (ethylene glycol) dimethacrylate, BisEMA: Ethoxylated bisphenol-A-glycol dimethacrylate, UDMA: urethane dimethacrylate, MMA: methyl methacrylate, S-PRG: Surface pre-reacted glass. ${ }^{*}$ The specific chemical identity and/or exact percentage (concentration) of this composition has been withheld as a trade secret.
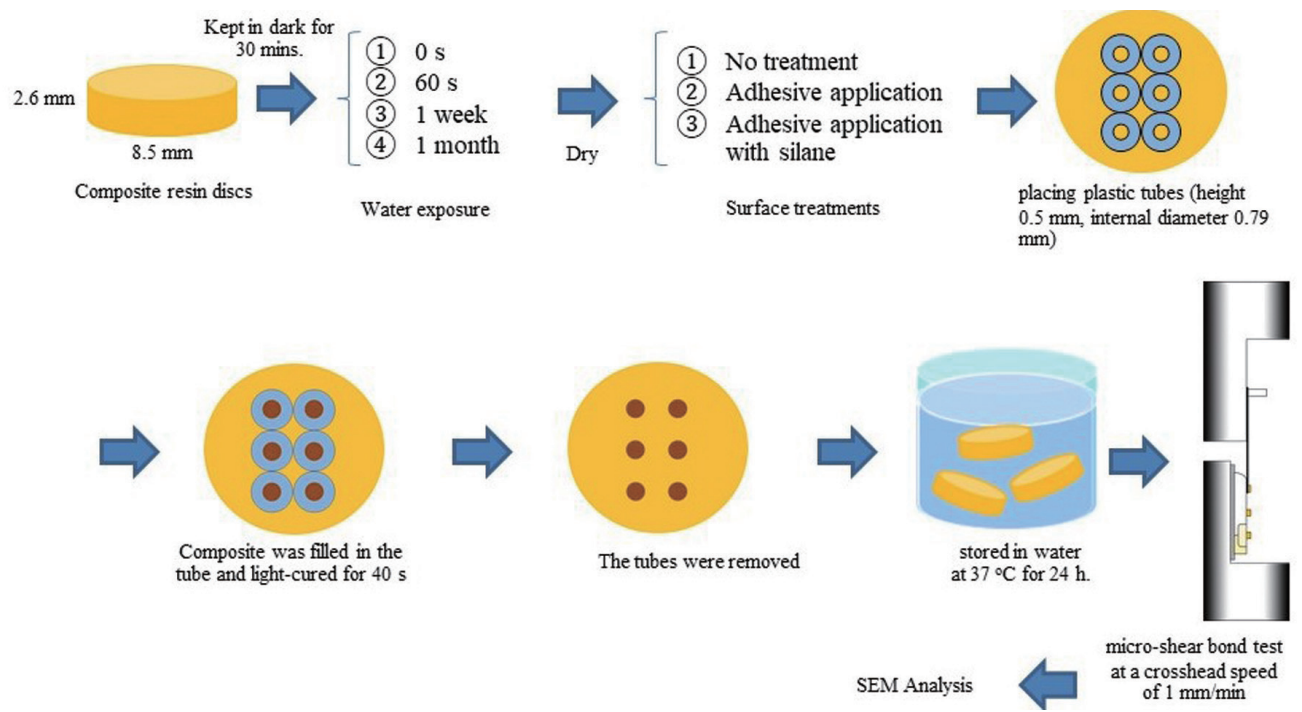

Fig. 1 Preparation methods for composite repair microshear bond test. 
a round-shaped mold $(8.5 \mathrm{~mm}$ in diameter and $2 \mathrm{~mm}$ in thick) was set on it. The molds were carefully filled with each resin composite and covered with a second plastic matrix strip and compressed with a thin glass cover slip (0.1 mm thick) in order to obtain a flat surface after light curing. The resin composite was light-cured for $40 \mathrm{~s}$ with a halogen light-curing unit (Optilux 501, Kerr, Orange, CA, USA), which had a light output greater than 600 $\mathrm{mW} \mathrm{cm}^{-2}$. The covering glass slip, and plastic strip were removed, and all the polymerized resin composite specimens were carefully removed from the molds. All the composite discs were then kept in a dark room for $30 \mathrm{~min}$ after which time they were stored in distilled water at $37^{\circ} \mathrm{C}$ for $0,60 \mathrm{~s}, 1$ week, or 1 month. We set the duration for water storage period to 1 month at the longest because it took less than 1 month for same size of composite resin specimens to fully absorb water from the pilot study (water sorption/solubility test, not shown). After each water storage period, the specimens were wiped off to remove water and air-dried using a dental three-in-one syringe for $30 \mathrm{~s}$. They were divided into 3 composite surface treatment groups as follows: (Group 1) no treatment; (Group 2) a one-step self-etch adhesive, Clearfil SE One (SEO; Kuraray Noritake Dental) was applied to the resin composite resin surface, air-dried for $5 \mathrm{~s}$, and then light-cured for $10 \mathrm{~s}$; (Group 3) the combination of SEO and a silane coupling agent (Clearfil Porcelain Bond Activator, Kuraray Noritake Dental) was applied, air-dried for $5 \mathrm{~s}$, and then lightcured for $10 \mathrm{~s}$.

After all the surfaces of the specimens were treated, 6 cylinders of the resin composite were placed on the surface of the same composite resin discs using thin discs of plastic microbore Tygon tubing (Saint-Gobain Performance Plastic, Nagano, Japan) with a $0.79 \mathrm{~mm}$ internal diameter and $0.5 \mathrm{~mm}$ height. After light-curing for $40 \mathrm{~s}$, all the plastic tubes were gently removed from each specimen. All of the specimens were then stored in distilled water at $37^{\circ} \mathrm{C}$ for $24 \mathrm{~h}$.

The specimens were then subjected to the $\mu$ SBS test using EZ test $500 \mathrm{~N}$ (Shimadzu, Kyoto, Japan) at a cross-head speed of $1 \mathrm{~mm} / \mathrm{min}$ as described by Shimada et al. ${ }^{10)}(n=12)$. The load of failure was used to calculate the $\mu \mathrm{SBS}$ in Megapascal (MPa). Subsequently, the surfaces of each fractured specimen were analyzed using a scanning electron microscope (SEM; JSM-5310, JEOL, Tokyo, Japan) at $\times 150$ magnification to determine failure modes of the specimens. The failure modes were classified into three categories: interfacial failure (more than $70 \%$ of the failure area is between composite disc and bonding resin or additional composite), cohesive failure (more than $70 \%$ of the failure area is within the composite, or adhesive resin), or mixed failure (combination of both types of interfacial failure and cohesive failure).

The $\mu$ SBS data were statistically analyzed using a three-way ANOVA (composite materials, exposure time, and surface treatments), and two-way ANOVA and $t$-test with Bonferroni's correction for 2 factors (surface treatments and exposure time, and surface treatments and composites) at a significance level of 0.05.

\section{Degree of conversion (DC)}

A transparent plastic matrix strip (Hawe Striproll Transparent $10 \mathrm{~mm}$, KerrHawe) was placed on the glass slab and a round-shaped mold $(15 \mathrm{~mm}$ in diameter and $1.0 \mathrm{~mm}$ in thick) was set on it. The molds were slightly overfilled with one of the 4 kinds of resin composites (FSU, ESQ, BE2, and APX). Then, a second plastic matrix strip was placed on the resin composite in the mold and compressed with a thin covering glass (0.1 $\mathrm{mm}$ thick). The resin composite was light-cured for 40 s with a halogen light-curing unit (Optilux501, Kerr) with a light output $>600 \mathrm{~mW} \mathrm{~cm}{ }^{-2}$. The glass slab and plastic strips were peeled off, and all the polymerized resin composite specimens were carefully removed from the molds. The specimens were stored in the dark in air at $37^{\circ} \mathrm{C}$ for $24 \mathrm{~h}$ after the completion of exposure.

Infrared Spectroscopy (IR) spectra of micro-areas $(100 \times 100 \mathrm{~mm})$ were measured in order to evaluate the quantity of remaining carbon-carbon double bonds in the specimens using a Fourier transform infrared spectrometer (JIR-100, JEOL) equipped with a microscopic unit fitted with an automatic mapping stage. The measurements were made at $0.25 \mathrm{~mm}$ intervals along the midline, from the irradiated surface to the base. In the IR spectra, two absorbance peaks appeared in the range, 1,600 to $1,650 \mathrm{~cm}^{-1}$. An appropriate baseline was drawn, and these two absorption peaks were separated into two Lorentzian curves. The intensities of absorption were determined by calculating the areas of the peaks. DC was calculated using the following equation:

DC $(\%)=100-(b c / a d \times 100)$

Where the intensities a- $d$ were defined as follows: a, $\mathrm{C}=\mathrm{C}$ absorbance peak at $1,637 \mathrm{~cm}^{-1}$ of resin pastes; $\mathrm{b}$, aromatic absorbance peak at $1,608 \mathrm{~cm}^{-1}$ of resin pastes; c, $\mathrm{C}=\mathrm{C}$ absorbance peak at $1,637 \mathrm{~cm}^{-1}$ of cured resins; and $\mathrm{d}$, aromatic absorbance peak at $1,608 \mathrm{~cm}^{-1}$ of cured resins. The data were analyzed using the Statistical Package for Statistical Science (SPSS Version 15.0). One-way ANOVA was performed to analyze variance and to look for differences among the groups, followed by Tukey's HSD (Honestly Significant Difference) post-hoc test. The significance difference was set at $\alpha=0.05$.

\section{RESULTS}

$\mu S B S$

There were no pretesting failures during specimen preparation for $\mu$ SBS testing. Table 2 shows the mean values and standard deviations of the $\mu$ SBS test. Threeway-ANOVA test revealed significant differences among the three factors, composite $(p<0.001)$, surface treatment $(p=0.006)$, and the duration of water storage $(p<0.001)$. There was a significant interaction among these three factors $(p=0.001)$. Significant interactions were found between composite materials and surface treatments for all storage times except 1 week $(p<0.05)$, and significant interactions between surface treatments and water storage period for the all tested composites except APX $(p<0.05)$. 
Table 2 Repair microshear bond strength of newly-filled composite to resin matrix in same cured composites after water aging

Filtek Supreme Ultra (FSU)

\begin{tabular}{ccccc}
\hline \multirow{2}{*}{$\begin{array}{c}\text { Composite surface } \\
\text { treatments }\end{array}$} & None & $60 \mathrm{~s}$ & \multicolumn{2}{c}{ Water aging of composite disk } \\
\cline { 2 - 5 } & $33.5 \pm 2.1^{\mathrm{ABCab}}$ & $23.7 \pm 6.9^{\mathrm{ADEc}}$ & $16.4 \pm 6.3^{\mathrm{BDab}}$ & 1 month \\
\hline No adhesive & $23.9 \pm 1.7^{\mathrm{a}}$ & $23.8 \pm 4.2$ & $20.4 \pm 6.6$ & $21.4 \pm 4.2^{\mathrm{ab}}$ \\
SE one & $25.4 \pm 5.5^{\mathrm{bcd}}$ & $23.2 \pm 8.2^{\mathrm{f}}$ & $22.4 \pm 4.4^{\mathrm{a}}$ & $21.3 \pm 2.8^{\mathrm{bg}}$ \\
SE one+Silane & & &
\end{tabular}

Estelite Sigma Quick (ESQ)

\begin{tabular}{|c|c|c|c|c|}
\hline \multirow{2}{*}{$\begin{array}{l}\text { Composite surface } \\
\text { treatments }\end{array}$} & \multicolumn{4}{|c|}{ Water aging of composite disk } \\
\hline & None & $60 \mathrm{~s}$ & 1 week & 1 month \\
\hline No adhesive & $29.5 \pm 2.1^{\mathrm{ABCab}}$ & $17.9 \pm 5.2^{\text {Ade }}$ & $14.7 \pm 4.3^{\mathrm{Bac}}$ & $14.4 \pm 4.7^{\text {Caef }}$ \\
\hline SE one & $21.8 \pm 3.7^{\mathrm{ab}}$ & $21.7 \pm 6.2$ & $19.5 \pm 5.5^{\mathrm{a}}$ & $19.3 \pm 4.4^{\mathrm{ac}}$ \\
\hline SE one+Silane & $19.8 \pm 4.3^{\text {bce }}$ & $19.3 \pm 4.1^{\mathrm{g}}$ & $17.9 \pm 6.2^{\mathrm{b}}$ & $16.4 \pm 4.1^{\mathrm{hi}}$ \\
\hline \multicolumn{5}{|l|}{ Beautifil II (BE2) } \\
\hline \multirow{2}{*}{$\begin{array}{l}\text { Composite surface } \\
\text { treatments }\end{array}$} & \multicolumn{4}{|c|}{ Water aging of composite disk } \\
\hline & None & $60 \mathrm{~s}$ & 1 week & 1 month \\
\hline No adhesive & $28.8 \pm 2.7^{\mathrm{A}}$ & $30.3 \pm 7.9^{\mathrm{Babd}}$ & $21.5 \pm 5.7^{\mathrm{ABd}}$ & $23.3 \pm 4.4^{\mathrm{ce}}$ \\
\hline SE one & $27.5 \pm 6.2^{\mathrm{Ab}}$ & $21.4 \pm 7.9^{\mathrm{a}}$ & $21.2 \pm 4.7^{\mathrm{A}}$ & $23.7 \pm 6.9$ \\
\hline SE one+Silane & $23.8 \pm 3.3^{\mathrm{f}}$ & $23.4 \pm 6.5^{\text {bh }}$ & $24.1 \pm 5.4$ & $23.9 \pm 4.7^{\mathrm{hj}}$ \\
\hline \multicolumn{5}{|l|}{ Clearfil AP-X (APX) } \\
\hline \multirow{2}{*}{$\begin{array}{l}\text { Composite surface } \\
\text { treatments }\end{array}$} & \multicolumn{4}{|c|}{ Water aging of composite disk } \\
\hline & None & $60 \mathrm{~s}$ & 1 week & 1 month \\
\hline No adhesive & $31.9 \pm 6.9$ & $36.3 \pm 5.0^{\text {ace }}$ & $29.0 \pm 9.8^{\mathrm{bcd}}$ & $31.5 \pm 5.4^{\mathrm{df}}$ \\
\hline SE one & $27.0 \pm 8.0$ & $26.9 \pm 5.8^{\mathrm{a}}$ & $22.8 \pm 7.4$ & $27.0 \pm 5.8^{\mathrm{bc}}$ \\
\hline SE one+Silane & $31.9 \pm 5.9$ & $32.4 \pm 6.2^{\mathrm{fgh}}$ & $28.8 \pm 9.3^{\mathrm{b}}$ & $31.4 \pm 4.4^{\mathrm{gij}}$ \\
\hline
\end{tabular}

Values are mean \pm SD. Upper-case letters refer to row. Lower-case letters refer to column. Same superscript letters indicate statistically significant differences in rows and columns $(p<0.05)$.

In the no water-storage group, for BE2 and APX, there were no significant differences in $\mu$ SBS between with and without application of one-step self-etch adhesive $(p>0.05)$, while the adhesive application significantly decreased the $\mu$ SBS of FSU and ESQ $(p<0.05)$. The $60 \mathrm{~s}$ water-storage period decreased the $\mu$ SBS of FSU and ESQ compared with no waterstorage (FSU; $p=0.01$, ESQ; $p=0.002$ ), and showed no significant difference in $\mu$ SBS between with and without the applications of one-step self-etch adhesive $(p>0.05)$. In the $60 \mathrm{~s}$ water-storage groups without adhesive application, ESQ had the lowest $\mu$ SBS among the materials. Moreover, 1-week of water-storage significantly reduced the $\mu \mathrm{SBS}$ of FSU $(p=0.01)$, although there were no significant differences between the $\mu$ SBS of FSU and ESQ after 1-week and 1-month water storage periods $(p>0.05)$. After 1-month water storage, the adhesive application significantly increased the $\mu$ SBS of FSU and ESQ $(p<0.05)$. On the other hand, for BE2 and APX, 1-month water-storage of the repaired cured-composite did not significantly affect the $\mu$ SBS $(p>0.05)$. The specimens of APX showed the highest $\mu$ SBS among the materials after 1 -month water storage in each application group. In the 1-month water-storage groups, the adhesive application did not affect the $\mu$ SBS of either BE2 or APX.

Adhesive application with a silane coupling agent did not significantly affect the $\mu \mathrm{SBS}$ of all the resin composites including FSU in all the experimental groups.

Failure mode analysis

Figure 2 shows the failure mode distributions of the debonded specimens. 
Filtek Supreme Ultra

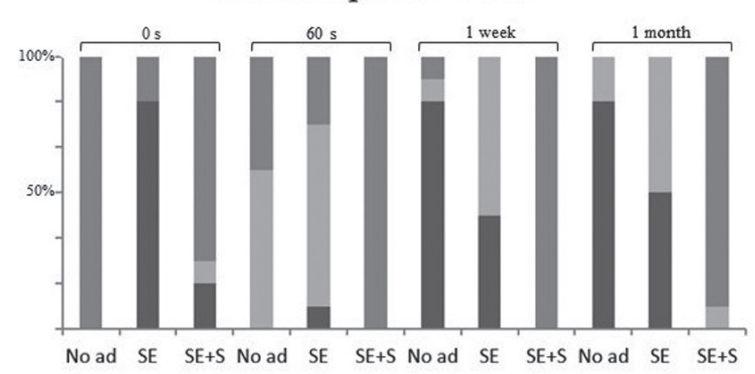

Beautifil II

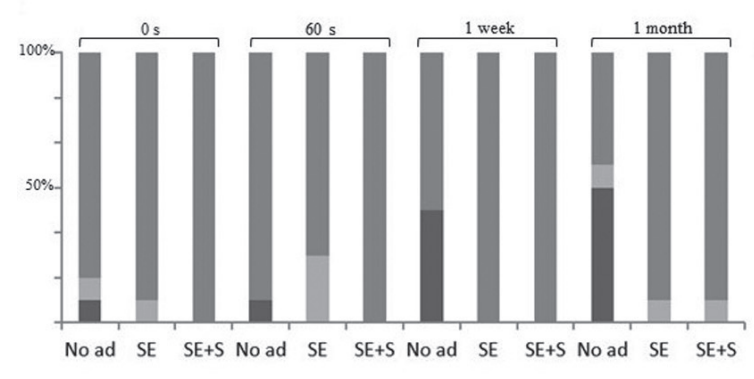

Interfacial

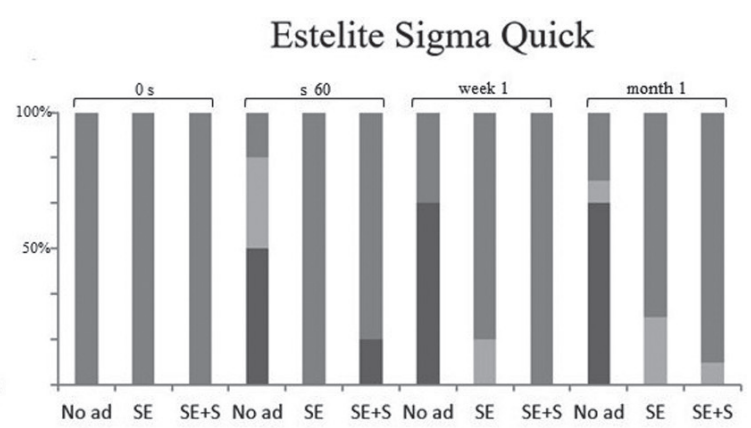

Clearfil AP-X

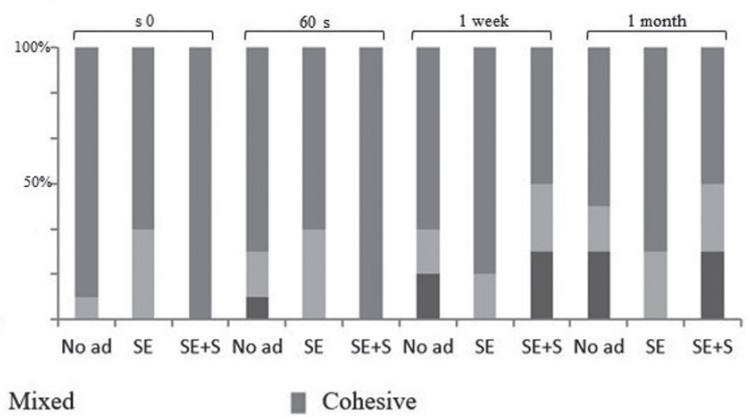

Fig. 2 SEM failure mode (\%) distribution in the experimental groups.

Every three consecutive bars in each brand chart represent one group of storage time.

No Ad: No adhesive application, SE: Clearfil SE One, S: a silane coupling agent.

Table 3 The degree of conversion (DC) of resin composites tested in this study

\begin{tabular}{ccccc}
\hline & $\begin{array}{c}\text { Filtek Supreme Ultra } \\
\text { (FSU) }\end{array}$ & $\begin{array}{c}\text { Estelite Sigma Quick } \\
\text { (ESQ) }\end{array}$ & $\begin{array}{c}\text { Beautifil II } \\
\text { (BE2) }\end{array}$ & $\begin{array}{c}\text { Clearfil AP-X } \\
\text { (APX) }\end{array}$ \\
\hline DC (\%) & $38.9 \pm 6.4^{\mathrm{a}}$ & $67.9 \pm 2.6^{\mathrm{b}}$ & $46.9 \pm 7.9^{\mathrm{c}}$ & $48.4 \pm 5.1^{\mathrm{c}}$ \\
\hline
\end{tabular}

Values are mean \pm SD. Different superscript letters indicate statistically significant differences $(p<0.05)$.

In the non-water storage group, non-adhesive application showed only cohesive failure in FSU and ESQ. However, the failure patterns of FSU changed from cohesive failure to interfacial failure with the application of adhesive in the non-water storage group. After $60 \mathrm{~s}$ water storage, half the specimens of ESQ failed at the adhesive interface, while for FSU, no specimens exhibited interfacial failure. After 1-week water-storage, the percentage of interfacial failures increased with an increase in the water storage period especially in FSU.

After 1-month of water storage of the repaired curedcomposite, adhesive application reduced the number of interfacial failures. For BE2 and APX, most of the failure patterns were cohesive failure irrespective of water-storage time or surface treatments. In the water storage groups, longer water storage times increased the number of interfacial failures of all the specimens. However, the percentages of the interfacial failures of the APX specimens were the lowest among the materials for each water-storage period. In the water storage groups, adhesive application reduced the number of interfacial failures among all the materials compared with non-adhesive application at each storage period. After 1-month water storage, no interfacial failures were observed in the ESQ, BE2 and APX groups with adhesive application.

$D C$

Table 3 shows the DC values (\%) obtained from each of the resin composites. The DC values beginning with the highest first, were: ESQ; $67.9( \pm 2.6) \%$, APX; $48.4( \pm 5.1) \%$, BE2; $46.9( \pm 7.9) \%$, FSU; $38.9( \pm 6.4) \%$. ANOVA and Tukey's HSD test revealed that there were significant differences among all the groups $(p<0.05)$ except between BE2 and APX $(p>0.05)$.

\section{DISCUSSION}

In this study, we investigated the influence of three experimental factors; resin composite materials, surface treatment methods and water-storage of repaired curedcomposite on the repair $\mu \mathrm{SBS}$ of newly-filled composite 
applied to the resin matrix of cured-composite. Significant differences in $\mu$ SBS were found among all the experimental groups. Thus, both null hypotheses tested in this study that 1) there is no difference in repair bond strength among resin composites with different DC, and that 2) water-storage does not affect the repair bond strength of resin composites with and without application of one-step self-etch adhesive, were rejected.

The existence of un-reacted $\mathrm{C}=\mathrm{C}$ double bonds in the cured-composite plays a crucial role in the bonding performance of the newly-filled resin composite ${ }^{11,12)}$. The amount of un-reacted monomers in cured-composite would rely mainly on the chemical composition of the resin matrix and its' polymerization behavior. Higher immediate composite-composite bond strength might occur as a result of plentiful un-reacted monomers in cured-composite ${ }^{13)}$. However, the un-reacted monomers in cured-composite are easily released and leached from resin matrix after aging in water, which is thought to adversely affect the composite-composite join ${ }^{14)}$. On the other hand, it is well-known that an oxygen-inhibited layer forms on the cured-composite, which affects the mechanical and chemical properties of the compositecomposite join ${ }^{15,16)}$ because un-reacted monomers in the oxygen-inhibited layer can co-polymerize with un-reacted monomers of newly-filled uncured-composite ${ }^{17)}$. In this study, we focused on the role of un-reacted monomers in the cured-composite on the bonding performance of the newly-filled uncured-composite to resin matrix of wateraged cured-composite. Therefore, the repaired composite surfaces were prepared and light-cured by covering with a transparent plastic strip to minimize formation of an oxygen-inhibited layer ${ }^{13,18}$ and the exposure of filler particles on the surface.

In general, fillers are thought not to be exposed at the top of free surfaces after light-curing under covers of plastic films or glass slides ${ }^{18)}$, because the filler surfaces are silanated and industrially bonded to resin monomers. However, FSU uses unique nanocluster fillers, which are loosely bound agglomerates of un-silanated nanosize silica and zirconia particles ${ }^{19}$. There is therefore the possibility that the fillers in FSU were exposed on the prepared surface when covered with the transparent plastic strip. Our pilot study indicated that when these fillers were exposed on the adhesive surface, the application of a silane coupling bonding agent (mixture of Clearfil SE One and Porcelain Bond Activator) could increase the $\mu \mathrm{SBS}$ of FSU. However, the application of a silane coupling bonding agent could not affect the $\mu \mathrm{SBS}$ of all the resin composites including FSU in all the experimental groups. Therefore, it was thought that the prepared surfaces of all the resin composite consisted of resin matrix in the cured-composite without filler exposure.

In the no water storage groups, BE2 and APX, there were no significant differences in $\mu$ SBS between with and without the application of one-step selfetch adhesive (Clearfil SE One). The application of an adhesive agent could improve the surface wettability on the cured-composite and enhance monomer diffusion into the cured-composite, leading to an increase in repair bond strength ${ }^{20)}$. However, in the no waterstorage group, the existence of un-reacted monomers in the cured-composite would not require the diffusion of further additional monomers with adhesive application into the cured-composite to obtain composite-composite adhesion. Additionally, Clearfil SE One contains ethanol and water as solvents. Surface contamination with the solvents on the cured-composite might counteract the positive effects of adhesive application on repair bond strength in the no water storage group. On the other hand, adhesive application significantly decreased the $\mu$ SBS to FSU and ESQ, and in particular, the failure pattern of FSU changed from cohesive failure to interfacial failure. These results indicate that the adhesive application had adverse effects on the cured-composite surface of FSU and ESQ, which were prepared by covering with a transparent plastic strip, when obtaining the compositecomposite join. Presumably, for FSU and ESQ, the covering-method with a plastic strip on resin composite surface could not completely prevent the formation of an oxygen-inhibited layer ${ }^{21,22)}$. In the no water-storage group of FSU and ESQ, the slight existence of an oxygeninhibited layer on the cured-composite surface might produce higher $\mu$ SBS without the adhesive application and ethanol/water present in Clearfil SE One could contaminate the oxygen-inhibited layer, leading to lower $\mu$ SBS following adhesive application.

Sixty-second water-storage followed by air-drying reduced the $\mu$ SBS of FSU and ESQ compared with no water-storage, and adhesive application had no adverse effects on their $\mu$ SBS. Presumably, even if the oxygeninhibited layer was slightly formed on the FSU and ESQ surfaces, there would hardly be an effect of the oxygen-inhibited layer on their $\mu$ SBS values in the $60 \mathrm{~s}$ water-storage groups because $60 \mathrm{~s}$ water-storage could contaminate the oxygen-inhibited layer. In the $60 \mathrm{~s}$ water-storage groups without adhesive application, ESQ showed the lowest $\mu$ SBS among the materials. Considering the results of the failure modes, for ESQ with the highest DC (67.9\%), half the specimens failed at the adhesive interface, while for FSU with the lowest DC (38.9\%), there were no de-bonded specimens exhibiting interfacial failure. Additionally, after water-storage, ESQ reduced in $\mu \mathrm{SBS}$ and exhibited an increase in the number of interfacial failures, while FSU significantly reduced in $\mu \mathrm{SBS}$ with dramatic increase in the number of interfacial failures, in which there were no significant differences between the $\mu$ SBS of FSU and ESQ after 1-week and 1-month of water storage. The DC value represents the quantity of carbon double bonds left unpolymerized ${ }^{23)}$. That is, the higher the DC value, the smaller the quantity of un-reacted monomers, which are present in the cured-composite. These results would indicate that the quantity of un-reacted monomers in the cured-composite affected immediate repair bond strength to the resin matrix of the curedcomposite, and that after water storage, the un-reacted monomers in the cured-composite could not play a 
significant role in repair bonding performance because the un-reacted monomers were leached during water storage $^{24,25)}$. After 1-month water-storage of the repaired cured-composite, the adhesive application of Clearfil SE One significantly increased the $\mu$ SBS of FSU and ESQ with a reduced number of interfacial failures. Clearfil SE One contains the hydrophilic monomer, HEMA. Therefore, adhesive application could enhance monomer diffusion into the water-aged cured-composite with few unreacted monomers and improves surface wettability for application of the hydrophobic composite ${ }^{20)}$.

For BE2 and APX with DC values of 46.9 and $48.4 \%$, 1-month water-storage of the repaired cured-composite did not significantly affect $\mu$ SBS. However, the number of interfacial failures increased with an increase in the water storage period. Additionally, in the 1-month waterstorage group, the adhesive application did not affect the $\mu$ SBS of BE2 and APX although it reduced the number of interfacial failures. These results would indicate that water-storage could slightly affect composite-composite join of BE2 and APX because the un-reacted monomers were leached. That is, after 1-month water storage of the repaired cured-composite, BE2 and APX with/ without the adhesive application would have a higher quality composite-composite join than FSU and ESQ with DC of 38.9 and $67.9 \%$. Therefore, the DC values of resin composite might not strongly affect the repair bond strengths to resin matrix of the water-aged curedcomposite. The resin matrix of APX, which had stable and high $\mu$ SBS even after 1-month water storage, may have an advantage for composite repair restoration. It could be speculated that various factors, such as monomer components, water uptake (water sorption and solubility), morphological and mechanical properties of the resin matrix, will affect repair bond strengths to resin matrix of the water-aged cured-composite to a greater or lesser effect. Surprisingly, in FSU and ESQ groups even after 1-month water-storage, in which most of specimens exhibited interfacial failure, $\mu$ SBSs were not zero MPa. Further research is indicated to evaluate the repair bond strength with different DC of each resin composite to explore the correlation between DC and $\mu$ SBS, and determine adhesion to the resin matrix of cured-composite after long-term aging, simulating clinical situations.

\section{CONCLUSIONS}

The quantity of un-reacted monomers in the repaired cured-composite contributed to the bonding performance of newly-filled uncured-composite to the resin matrix of cured-composite without water storage, and the application of a one-step self-etch adhesive could not improve their repair bonding performances. Following 1-month water storage of the repaired cured-composite, FSU and ESQ exhibited reduced repair bonding performance to the resin matrix of the cured-composite, but adhesive application could improve their repair bond strengths. On the other hand, BE2 and APX did not exhibit significantly reduced repair bond strengths to resin matrix of the water-aged cured-composite, but the quality of the composite-composite join slightly deteriorated, in which the adhesive application did not increase repair bond strengths. For water-aged curedcomposite resins, the repair bond strength was no longer affected by the amount of initially residual un-reacted resin monomers.

\section{ACKNOWLEDGMENTS}

This work was supported by Grant-in-Aid for Scientific Research (C) \#26462873, Grant-in-Aid for Scientific Research (C) \#15K11108 from Ministry of Education, Culture, Sports, Science and Technology of Japan. This reseach work was partially supported by Chiang Mai University.

\section{REFERENCES}

1) Momoi Y, Hayashi M, Fujitani M, Fukushima M, Imazato S, Kubo S, Nidaido T, Shimizu A, Unemori M, Yamaki C. Clinical guidelines for treating caries in adults following a minimal intervention policy - evidence and consensus based report. J Dent 2012; 40: 95-105.

2) Hickel R, Manhart J. Longevity of restorations in posterior teeth and reasons for failure. J Adhes Dent 2001; 3: 45-64.

3) Brendeke J, Ozcan M. Effect of physicochemical aging conditions on the composite-composite repair bond strength. J Adhes Dent 2007; 9: 399-406.

4) Ozcan M, Barbosa SH, Melo RM, Galhano GA, Bottino MA. Effect of surface conditioning methods on the microtensile bond strength of resin composite to composite after aging conditions. Dent Mater 2007; 23: 1276-1282.

5) Sau CW, Oh GS, Koh H, Chee CS, Lim CC. Shear bond strength of repaired composite resins using a hybrid composite resin. Oper Dent 1999; 24: 156-161.

6) Rodrigues SA Jr, Ferracane JL, Della Bona A. Influence of surface treatments on the bond strength of repaired resin composite restorative materials. Dent Mater 2009; 25: 442451.

7) Krejci I, Lieber CM, Lutz F. Time required to remove totally bonded tooth-colored posterior restorations and related tooth substance loss. Dent Mater 1995; 11: 34-40.

8) Truffier-Boutry D, Place E, Devaux J, Leloup G. Interfacial layer characterization in dental composite. J Oral Rehabil 2003; 30: 74-77.

9) Velazquez E, Vaidyanathan J, Vaidyanathan TK, Houpt M, Shey Z, Von Hagen S. Effect of primer solvent and curing mode on dentin shear bond strength and interface morphology. Quintessence Int 2003; 34: 548-555.

10) Shimada Y, Kikushima D, Tagami J. Micro-shear bond strength of resin-bonding systems to cervical enamel. Am J Dent 2002; 15: 373-377.

11) Cornelio RB, Wikant A, Mjosund H, Kopperud HM, Haasum J, Gedde UW, Örtengren UT. The influence of bis-EMA vs bis-GMA on the degree of conversion and water susceptibility of experimental composite materials. Acta Odontol Scand 2014; 72: 440-447.

12) Giannini M, Seixas CA, Reis AF, Pimenta LA. Six-month storage-time evaluation of one-bottle adhesive systems to dentin. J Esthet Restor Dent 2003; 15: 43-48; discussion 9.

13) Li J. Effects of surface properties on bond strength between layers of newly cured dental composites. J Oral Rehabil 1997; 24: 358-360.

14) Imbery TA, Gray T, DeLatour F, Boxx C, Best AM, Moon PC. Evaluation of flexural, diametral tensile, and shear bond 
strength of composite repairs. Oper Dent 2014; 39: E250260.

15) Padipatvuthikul P, Mair LH. Bonding of composite to water aged composite with surface treatments. Dent Mater 2007; 23: 519-525.

16) Costa TR, Ferreira SQ, Klein-Junior CA, Loguercio AD, Reis A. Durability of surface treatments and intermediate agents used for repair of a polished composite. Oper Dent 2010; 35: 231-237.

17) Yamaji A, Tsujimoto A, Asaoka T, Matsuyoshi S, Tsuchiya K, Takamizawa T, Miyazaki M. Effect of oxygen inhibition in two-step self-etch systems on surface free energy and dentin bond strength with a chemically cured resin composite. J Oral Sci 2014; 56: 201-207.

18) Shawkat ES, Shortall AC, Addison O, Palin WM. Oxygen inhibition and incremental layer bond strengths of resin composites. Dent Mater 2009; 25: 1338-1346.

19) Curtis AR, Shortall AC, Marquis PM, Palin WM. Water uptake and strength characteristics of a nanofilled resinbased composite. J Dent 2008; 36: 186-193.
20) Irmak O, Celiksoz O, Yilmaz B, Yaman BC. Adhesive system affects repair bond strength of resin composite. J Istanb Univ Fac Dent 2017; 51: 25-31.

21) Park SH, Noh BD, Ahn HJ, Kim HK. Celluloid strip-finished versus polished composite surface: difference in surface discoloration in microhybrid composites. J Oral Rehabil 2004; 31: 62-66.

22) Park HH, LEE IB. Effect of glycerin on the surface hardness of composites after curing. J Korean Acad Conserv Dent 2011; 36: 483-489.

23) Galvao MR, Caldas SG, Bagnato VS, de Souza Rastelli AN, de Andrade MF. Evaluation of degree of conversion and hardness of dental composites photo-activated with different light guide tips. Eur J Dent 2013; 7: 86-93.

24) Fan PL, Edahl A, Leung RL, Stanford JW. Alternative interpretations of water sorption values of composite resins. J Dent Res 1985; 64: 78-80.

25) Toledano M, Osorio R, Osorio E, Fuentes V, Prati C, GarciaGodoy F. Sorption and solubility of resin-based restorative dental materials. J Dent 2003; 31: 43-50. 